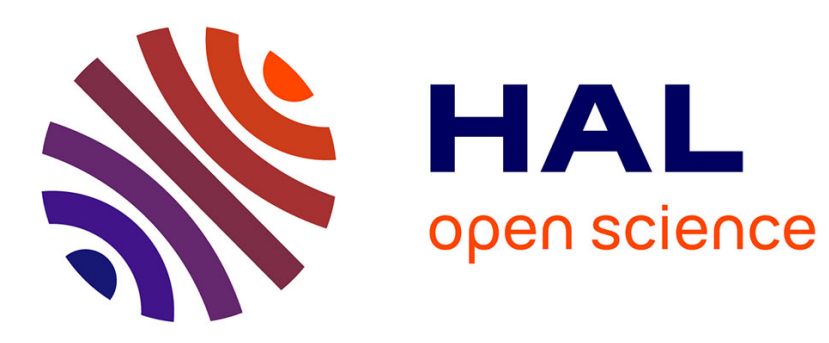

\title{
Revisiting binding of plutonium to transferrin by CE-ICP-MS
}

Sandrine Sauge-Merle, David Lemaire, Robert W Evans, C. Berthomieu, Jean Aupiais

\section{- To cite this version:}

Sandrine Sauge-Merle, David Lemaire, Robert W Evans, C. Berthomieu, Jean Aupiais. Revisiting binding of plutonium to transferrin by CE-ICP-MS. Dalton Transactions, 2017, 46, pp.1389-1396. 10.1039/c6dt04336d . hal-01451680

\section{HAL Id: hal-01451680 https://hal-amu.archives-ouvertes.fr/hal-01451680}

Submitted on 24 Apr 2018

HAL is a multi-disciplinary open access archive for the deposit and dissemination of scientific research documents, whether they are published or not. The documents may come from teaching and research institutions in France or abroad, or from public or private research centers.
L'archive ouverte pluridisciplinaire HAL, est destinée au dépôt et à la diffusion de documents scientifiques de niveau recherche, publiés ou non, émanant des établissements d'enseignement et de recherche français ou étrangers, des laboratoires publics ou privés. 


\title{
Revisiting Binding of Plutonium to Transferrin by CE-ICP-MS
}

\author{
Sandrine Sauge-Merle ${ }^{\mathrm{a}}$, David Lemaire ${ }^{\mathrm{a}}$, Robert W Evans ${ }^{\mathrm{b}}$, Catherine Berthomieu ${ }^{\mathrm{a}}$, Jean Aupiais*c \\ ${ }^{a}$ CEA, CNRS, Aix-Marseille Université, UMR 7265 Biologie Végétale et Microbiologie \\ Environnementales, Laboratoire des Interactions Protéine Métal, 13108 Saint-Paul-lez-Durance, \\ France \\ ${ }^{b}$ Doctor-on-a-Chip Laboratory, Electronic and Computer Engineering, College of Engineering, Design \\ and Physical Sciences, Brunel University, Uxbridge, Middlesex, UK, UB8 3PH \\ ${ }^{c}$ CEA, DAM, DIF, F-91297 Arpajon, France
}

\begin{abstract}
Capillary electrophoresis coupled with an inductively coupled plasma mass spectrometer has been applied for the first time to determine the binding constant of human transferrin (Tf) for tetravalent plutonium. The experiments were carried out in the buffer 2-( $\mathrm{N}$ morpholino)ethanesulfonic acid (MES) at $\mathrm{pH} 6,0.1 \mathrm{M} \mathrm{NaCl}$ and $25{ }^{\circ} \mathrm{C}$. The nitrilotriacetate anion (NTA) used in this study prevents the hydrolysis of plutonium and is also an ideal competitor with Tf for $\mathrm{Pu}$, both ligands sharing a comparable binding strength. The separation shows unambiguously two peaks associated with the complex $\mathrm{Pu}(\mathrm{NTA})_{2}$ used as initial species and with Pu-transferrin. Two series of independent experiments were conducted and gave the first stepwise conditional bicarbonate-free Pu-transferrin binding constant equal to $\log K_{1}^{*}=22.50 \pm 0.19$. In absence of bicarbonate the affinity of transferrin for plutonium at $\mathrm{pH} 6$ is about $10^{4}$ times stronger than that of iron at pH $6.7\left(\log K_{1}^{*}=18.06\right)$.
\end{abstract}

\section{IINTRODUCTION}

The development of the civil and military nuclear industry for energy production or military applications could lead to a possible release of radionuclides into the environment which can constitute a major hazard for ecosystems and human health. One of the main radionuclides is plutonium ( $\mathrm{Pu}$ ), a radiotoxic element with no known physiological function. It could be strongly retained by organisms and cause health problems. ${ }^{1-3}$ In humans this element accumulates in bones and liver before being slowly and partially excreted in the urine and faeces. ${ }^{4,}{ }^{5}$ It could be also transported in blood bound by serum transferrin (Tf) ${ }^{6-8}$ Tf is a glycoprotein with a molecular mass around $80 \mathrm{kDa}$, comprising two globular lobes ( $\mathrm{N}$-lobe and $\mathrm{C}$-lobe), which transports ferric ion in the blood. Each lobe is divided into two domains and the cleft between the latter contains the metalbinding site which is able to bind one ferric iron. ${ }^{9}$ The metal coordination involves four protein ligands, the sidechains of aspartic acid, histidine and two tyrosine residues and is completed by an obligatory synergistic anion. ${ }^{10}$ This latter anion plays a key role in the iron binding site and in its absence the iron binding is weak. ${ }^{9}$ The physiological synergistic anion is carbonate (or bicarbonate) but other anions as oxalate or nitrilotriacetate can also complete the Fe coordination sphere. ${ }^{11}$ It is not surprising that Tf is able to bind plutonium in place of iron because both metals are "hard cations" according to the Pearson classification. Consequently, they prefer hard electron donors, such as oxygen, and they share remarkably similar behaviours in biological systems (transport and distribution). ${ }^{12,}{ }^{13}$ In blood plasma only about $30 \%$ of the metal-binding sites on transferrin are occupied by iron ${ }^{14}$ so that the remaining metal-binding sites are available for binding and 
transporting other metals such as titanium, vanadium, chromium, ruthenium, bismuth, manganese, aluminium, gallium, indium and actinides such as uranium or plutonium. ${ }^{10,15,16}$

Recent results show an internalization of $\mathrm{Pu}$ in mammalian cells through the common Fe uptake pathway involving receptor-mediated endocytosis of the transferrin loaded with Pu-Fe. ${ }^{6}$ Therefore, it is very important to determine the binding affinity of Tf for Pu. This binding affinity indicates the interaction strength between $\mathrm{Pu}$ and $\mathrm{Tf}$ and hence, it could give hints on $\mathrm{Pu}$ toxicity thresholds or $\mathrm{Pu}$ contaminations leading to the formation of Pu-Tf complexes that could be internalized in cells. Furthermore, it will set the basis for the optimisation of selective chelating agents able to compete with Tf for Pu binding in blood.

The binding of metals to a protein can be monitored by several techniques, such as fluorescence spectroscopy, isothermal titration calorimetry (ITC), time-resolved laser spectroscopy (TRLS), capillary electrophoresis coupled with an inductively coupled plasma mass spectrometer (CE-ICP$\mathrm{MS})$, and a binding constant expressed as $K_{d}, \log K$, or $\mathrm{p} K_{d}$ can be determined. ${ }^{17-20}$ This overall constant reflects the protein's affinity for the metal whatever the number of metal binding sites. A small $K_{d}$ or a high $\log K$ means that the protein's affinity for the metal is strong. If the protein has two binding sites, as is the case for transferrin, it is possible to assign a $K_{1}$ constant corresponding to the first metal binding (on either the lobe $\mathrm{C}$ - named $K_{1, C}$ - or the lobe $\mathrm{N}$ - named $K_{1, N}$ ) and a second constant $K_{2}$ for the binding of the remaining site (named $K_{2, C}$ or $\left.K_{2, N}\right)^{21}$

During her PhD thesis, Yule characterized the binding of $\mathrm{Pu}$ to Tf using UV-Visible difference spectroscopy and ultrafiltration. ${ }^{7}$ She obtained a $\mathrm{p} K_{d}$ equal to $21.25 \pm 0.75$ (standard deviation) indicating that $\mathrm{Tf}$ has a strong affinity for Pu. This value is now unanimously accepted by the scientific community and is quoted in other studies. ${ }^{6}$ It should be noted that there is no new data concerning the Pu-Tf binding because it is difficult to manipulate the highly radioactive element $\mathrm{Pu}$ and only a few laboratories have the authorization to use it. In this work, we revisited the determination of the Tf-Pu binding constant by using for the first time for this purpose a coupling between the capillary electrophoresis and an inductively coupled plasma mass spectrometry (CE-ICP-MS). This method presents several advantages such as a high separation efficiency of $C E$, a sensitive detection of ICP$\mathrm{MS}$ with a detection limit down to $10^{-12} \mathrm{M}$ for $\mathrm{Pu}^{22}$ and the use of low protein and metal quantities. This latter point is particularly interesting when using highly radioactive metals which could be dangerous and difficult (or impossible) to manipulate in higher quantities. The method was adapted using a coated capillary to avoid capillary clogging with proteins and controlling the Pu speciation using the anion nitrilotriacetate (NTA) to prevent Pu hydrolysis. ${ }^{23}$ Furthermore, the NTA was the suitable ligand because it has a binding strength for Pu equivalent to that of Tf-Pu allowing an ideal competition between Tf and NTA for Pu. ${ }^{23}$ This has allowed a determination of the conditional binding constant of $\mathrm{Tf}$ for Pu and is the first time that such a constant has been determined for $\mathrm{Pu}$ using CE-ICP-MS. The method was very reproducible considering the results of two sets of independent experiments. To compare and discuss our results with some of those found in the literature, the bicarbonate contribution was subtracted from the conditional binding constant leading to a bicarbonate-free binding constant. The comparison with iron will be discussed. 


\section{口ESULTS AND DISCUSSION}

Tetravalent actinides are known to be extremely sensitive to hydrolysis at physiological $\mathrm{pH}^{6}{ }^{6}$ To avoid undesired hydrolysis reactions during the complexation of $\mathrm{Pu}^{4+}$ by human transferrin, the solution should contain plutonium bound to a chelator with a high affinity for the metal. Moreover, in view of the specific mechanism of metal ions by transferrin, a synergistic anion is mandatory. ${ }^{9}$ The nitrilotriacetate anion presents two major advantages: it has a strong affinity for plutonium $\left(\log \beta_{2}=\right.$ 37.90 for the reaction $\left.P u^{4+}+2 N T A^{3-} \rightleftharpoons P u(N T A)_{2}^{2-}\right)^{23}$ and it acts as a synergistic anion with transferrin for several metal ions ${ }^{26-28}$ including $\mathrm{Pu}^{4+} .29,30$

The binding constant of the Pu-Tf complex has been determined by studying its competition with $\mathrm{Pu}$ NTA, using CE-ICP-MS to separate and quantify each complex, according to the Tf concentration in the sample. Pu and NTA concentrations were fixed and Tf concentration was varied from $0.627 \mathrm{mM}$ to $12.5 \mathrm{nM}$. The concentration of NTA $(1 \mu \mathrm{M})$ and the $\mathrm{pH}$ of experiments $(\mathrm{pH} 6)$ were chosen both to protect $\mathrm{Pu}$ against hydrolysis and to be able to detect the competition between Tf and NTA for $0<$ $[\mathrm{Tf}]<0.627 \mathrm{mM}$. In each experiment, two peaks were detected which were attributed to $P u(N T A)_{2}^{2-}$ and PuTf, respectively (Figure 1). The peak areas varied from $100 \% \mathrm{Pu}(N T A)_{2}^{2-}$ at zero Tf concentration down to $0 \%$ at $0.627 \mathrm{mM}$ Tf concentration. The opposite behavior was observed for the peak area of $P u T f$, as shown in Figure 2.

Based on the data in Table 1, $\mathrm{Pu}(N T A)_{2}^{2-}$ is the major species in solution (100\%) at $\mathrm{pH}=6.0$ and $\mathrm{C}_{\mathrm{NTA}}=1 \mu \mathrm{M}$. Therefore, only the equilibrium below is considered (charge omitted):

$$
\begin{aligned}
& P u(N T A)_{2}+T f \rightleftharpoons P u T f+2 N T A, \\
& \text { With } K^{*} \text { the conditional constant defined as } K^{*}=\frac{[P u T f][N T A]^{2}}{[T f]\left[P u(N T A)_{2}\right]}
\end{aligned}
$$

At the inflexion point of the sigmoidal function ${ }^{23}$ in Figure 2 , the $\left[\mathrm{Pu}(\mathrm{NTA})_{2}\right]$ and [PuTf] concentrations are equal. Thus Eq.(2) simplifies to:

$$
K^{*}=\frac{[N T A]^{2}}{[T f]}=\frac{\left(C_{N T A} / \alpha\right)^{2}}{C_{T f}},
$$

with $\mathrm{C}_{\mathrm{NTA}}$ and $\mathrm{C}_{\mathrm{Tf}}$ the total concentration of ligand, the coefficient $\alpha$ is defined as:

$$
\begin{array}{r}
\alpha=\frac{C_{N T A}}{\left[N T A^{3-}\right]}= \\
1+10^{p k a_{4}}\left[H^{+}\right]+10^{p k a_{4}+p k a_{3}}\left[H^{+}\right]^{2}+10^{p k a_{4}+p k a_{3}+p k a_{2}}\left[H^{+}\right]^{3}+10^{p k a_{4}+p k a_{3}+p k a_{2}+p k a_{1}}\left[H^{+}\right]^{4}
\end{array}
$$

where $\mathrm{pka}_{\mathrm{i}}$ stands for the four stepwise dissociation constants of nitrilotriacetic acid (see Table 1). Under our experimental conditions $(\mathrm{pH}=6.0), \log _{10} \alpha$ is equal to $3.68 \pm 0.04$.

From Eq.(3) and the constant of formation of $\mathrm{Pu}(\mathrm{NTA})_{2}$, the conditional constant relative to the formation of PuTf can be deduced:

$$
\log _{10} K_{P u T f}^{*}=\log _{10} K^{*}+\log _{10} K_{P u(N T A)_{2}}
$$

Two sets of independent experiments were performed by using two different types of coated capillaries layer generating a hydrophilic surface, i.e. $\mathrm{N}-\mathrm{CHO}^{\mathrm{TM}}$ (polyvinyl alcohol (PVA) layer) and Neutral $^{\mathrm{TM}}$ (polyacrylamide layer) capillary, to avoid the capillaries becoming clogged by proteins. The 
resulting conditional constants of Pu-Tf obtained at $\mathrm{pH} 6, \mathrm{I}=0.1 \mathrm{M}$ and $25{ }^{\circ} \mathrm{C}$, were $\log _{10} K_{\text {PuTf }}^{*}=$ $24.62 \pm 0.24$ and $24.89 \pm 0.26$ respectively (Table 2 ). The values obtained are very similar and show that the CE-ICP-MS method used in this study is very efficient and reproducible.

Schlabach and Bates showed that bicarbonate anions drive nitrilotriacetate anions out of the transferrin-Fe ${ }^{3+}-\mathrm{NTA}$ ternary complex. ${ }^{31}$ Since $\mathrm{Pu}^{\mathrm{IV}}$ and $\mathrm{Fe} \mathrm{III}^{\mathrm{II}}$ are known to behave similarly due to a similar charge to size ratio (4.6 and 4.3, respectively), ${ }^{12}$ the same behavior is assumed for the transferrin-Pu ${ }^{4+}$-NTA complex. Therefore, in order to compare our results with other data obtained at different bicarbonate concentrations, we used the bicarbonate-independent binding constant $\left(K_{1}^{*}\right)^{3}{ }^{32}$

$$
\log _{10} K_{1}^{*}=\log _{10} K_{P u T f}^{*}+\log _{10} \alpha_{c},
$$

where $\alpha_{c}$ is the fractional saturation of the human apo-transferrin-binding sites with bicarbonate according to the equation:

$$
\alpha_{c}=K_{c} \frac{\left[\mathrm{HCO}_{3}^{-}\right]}{1+K_{c}\left[\mathrm{HCO}_{3}^{-}\right]^{\prime}}
$$

with $K_{c}$ the binding constant of bicarbonate with transferrin.

By analogy with $\mathrm{Fe}^{3+}$, only Pu complexation on the C-terminal site of $\mathrm{Tf}$ is considered due to both a higher affinity constant and a preferential loading at the C-terminal site using NTA as the synergistic anion at $\mathrm{pH} 6 .^{33}$ It is worthy of note that at $\mathrm{pH}<6.1$, Chasteen and co-workers showed no observable iron loading at the $\mathrm{N}$-terminal site in $1 \mathrm{mM} \mathrm{NaHCO} / 50 \mathrm{mM}$ MES buffer. ${ }^{21}$ These data indicate that under our conditions $\mathrm{Pu}$ is very likely loaded at the $\mathrm{C}$-terminal site. As a result we use the binding constant of bicarbonate with transferrin for the C-terminal site $\log K_{C}=2.66 \pm 0.07$ and not that related to the $\mathrm{N}$-terminal site (i.e. $\log K_{N}=1.8 \pm 0.3$ ). ${ }^{34}$

The bicarbonate concentration in the BGE was analyzed by ionic chromatography on two aliquots. Bicarbonate concentrations of 1.25 and $1.05 \mathrm{mg} / \mathrm{L}$ were found corresponding to an average molar concentration of $1.8810^{-5} \mathrm{M}$. As a result, $\log _{10} \alpha_{c}=-2.25 \pm 0.11$. The conditional binding constants recalculated bicarbonate-free for the two independent experiments were $\log _{10} K_{P u T f}^{*}=22.37 \pm 0.26$ and $22.64 \pm 0.28$ given an average of $22.50 \pm 0.19$ (Table 3 ).

These results are comparable to those obtained by Yule $\left(\log K^{*}=21.25 \pm 0.75\right){ }^{7}$ It is worth noting, however, that the conditions used by Yule were different, with a higher $\mathrm{pH}$ (7.4), a lower ionic strength $(0.05 \mathrm{M})$ and the presence of a different synergistic anion (citrate). However, several points were not addressed which could modify this $\mathrm{p} K_{d}$ value. Indeed, at the Pu concentration used in the study by Yule, several undesirable reactions may occur, such as disproportionation, polymerization and radiolysis. As a result, the plutonium speciation, and in particular the presence of only tetravalent plutonium (Pu(IV)), was not proven. In addition, Yule used citrate as a synergistic anion but could not determine the formation constant of the Pu-citrate complex. Therefore, a correlation model between Fe and $\mathrm{Pu}$ was applied to deduce Pu-citrate interaction properties and hence the competition between citrate and transferrin for Pu binding. The value originally written by Yule and quoted by Jensen et al was $\log K^{*}=21.25 \pm 0.75$. ${ }^{6}$ Actually eight different $\log _{10} K^{*}$ values were given by Yule in her thesis that varied from $\log _{10} K^{*}=21.75$ to 24 . The average is not consistent with the value selected by Jensen et al. nor is the uncertainty, which is in fact a standard deviation (using $\mathrm{n}=$ 8). From the eight values determined, we recalculated a more correct value and its uncertainty, at a 
$95 \%$ confidence level, which is now: $\log K^{*}=22.45 \pm 0.62$. However, there are several points which must be addressed. Yule considered the citrate anion as a synergistic anion although Schlabach and Bates showed that the citrate anion was ineffective as a synergistic anion. ${ }^{31}$ Therefore, the concentration of bicarbonate should have been taken into account in Yule's experiments. Although the concentration of bicarbonate was given in her thesis for the transferrin stock solution, there was no clear information concerning the $\mathrm{pH}$ adjustment of the Pu-citrate stock solution. It was either adjusted by an alkaline solution $(\mathrm{NaOH})$ or by a stock solution containing bicarbonate. The first case leads to an unchanged value for the concentration of bicarbonate whereas the second case requires a recalculation of the concentration of free bicarbonate in all the experiments. The final result gave a recalculated bicarbonate-free conditional binding constant of $22.32 \pm 0.65$ which can be considered as not being significantly different from the previous one. Our value and that of Yule are very similar even if they cannot be rigorously compared. Indeed, usually several equilibria may occur for this chemical system:

1) $P u+T f \rightleftharpoons P u_{C} T f$,

for the complexation on the C-terminal site, with the corresponding convention $K_{1}^{*}$ or $K_{C}^{*}$ or $K_{1, C}^{*}$ for the binding constant.

2) $P u+T f \rightleftharpoons T f P u_{N}$

for the complexation on the $\mathrm{N}$-terminal site with the corresponding convention $K_{1}^{*}$ or $K_{N}^{*}$ or $K_{1, N}^{*}$.

3) $P u_{C} T f+P u \rightleftharpoons P u_{C} T f P u_{N}$,

or

4) $T f P u_{N}+P u \rightleftharpoons P u_{C} T f P u_{N}$,

for the second stepwise reaction with the corresponding convention $K_{2}^{*}$ or $K_{2, N}^{*}$ (Eq.10a) or $K_{2, C}^{*}$ (Eq.10b).

5) $P u+T f \rightleftharpoons P u T f$,

for the overall complexation (the number of sites is not considered), with the corresponding convention $K^{*}$.

The question to be addressed is what equilibria may be involved in the Yule thesis. Unfortunately, it is not possible to assign any equilibrium because an overall constant (Eq.11) had been determined. According to the data provided in Table 2, the molar ratio Pu/Tf used by Yule varied from 0.5 to 4 . It seems reasonable to assume, based on the chemical behavior of iron, that equilibria (8), (9) and (10 a\&b) were present. This problem can be addressed by two approaches.

Firstly, based on Chasteen and coworkers results on iron and applied for plutonium, ${ }^{21}$ it is possible to propose a distribution of Pu between the two binding sites of $\mathrm{Tf}$ in the experiments of Yule. About 30 $\%$ of iron (and therefore $\mathrm{Pu}$ ) is bound to the $\mathrm{N}$-lobe and $70 \%$ to the $\mathrm{C}$-lobe. Both sites can be considered as roughly equivalent and independent for iron binding and a $K_{1}^{*}$ constant can be determined. This would suggest that Pu also interacts with both the $\mathrm{C}$ and $\mathrm{N}$ sites in the experiments of Yule. Yule used concentrations of plutonium ranging from 5.8 to $46.5 \mu \mathrm{M}$ in her experiments, for a 
constant transferrin concentration of $11.6 \mu \mathrm{M}$. The highest $\mathrm{Pu} / \mathrm{Tf}$ molar ratio $(\mathrm{Pu} / \mathrm{Tf}=4)$ in the experiments of Yule suggests that probably a second plutonium atom is bound to the other site and therefore the equilibria (10 a) and (10b) should be considered. To solve this problem, a second complementary approach has been used.

By using the correlation developed by Sun and co-workers, ${ }^{35}$ and applied by Ansoborlo and coworkers for actinides, ${ }^{12}$ the overall estimated binding constant ( $\log K^{*}=22.7$, Eq.(12) using data in the reference ${ }^{12}$ is consistent with the value given by Yule (Table 2). This means that the extended relation developed by Ansoborlo and co-workers to provide new correlations for the $\mathrm{C}$ - and $\mathrm{N}$ terminal sites with actinides can be applied. In addition, the second stepwise constant log $K_{2}^{*}$ (Eq 10a $\& 10 \mathrm{~b})$ is generally one $\log$ unit lower than $\log K_{1}^{*} .^{33}$ In practice the correlation between both constants is very good, as depicted in Figure $3\left(r^{2}=0.996\right.$ from data in reference). ${ }^{33}$ Therefore, a speciation diagram based upon the data of Ansoborlo et al, calculated $K_{2, C}^{*} K_{2, N}^{*}$ binding constants for $\mathrm{Pu}$, shows that several equilibria, namely (8), (9) and (10a or 10b) are present in the experiments of Yule (Figure 4). As a consequence, both approaches reveal that an overall binding constant $K^{*}$ (Eq.11) has been determined by Yule.

Sun and coworkers found a good correlation between $K_{1}^{*}$ and the first hydrolysis of the metal (Figure 5). We have included other values for $\mathrm{Fe}^{3+}$ because it seems that the value from the initial calculation performed by Sun et al using the data of Aisen et al was a little high. As seen in Figure 5, the value of Yule $\left(\log _{10} K_{\mathrm{FeTf}}^{*}=20.37 \pm 0.54\right)$ for Fe is in agreement with the value of Aisen et al (19.5) whereas that of Martin et al (21.8) is a little higher. In any case, calculations based on the correlation between Fe- and Pu- interactions with the $\mathrm{C}$ and $\mathrm{N}$ lobes should be taken with great care because the hydrolysis of $\mathrm{Pu}$ is of more important than that of iron or that of all other metals used for the correlation, in a region where no other data are present (see Figure 5). For instance, new data, not considered in the review of Ansoborlo et al, led to the recommendation of the use of $\log \mathrm{K}_{\mathrm{Pu}-\mathrm{H}_{2} \mathrm{O}}=-$ $(0.60 \pm 0.20)^{36}$ in 2003 , which corresponds to a significant increase as compared to the value of $(0.78 \pm 0.60)^{37}$ recommended in 2001 .

$$
\log _{10} K_{1}^{*}=2.05 \times \log _{10} K_{\mathrm{Pu}-\mathrm{H}_{2} \mathrm{O}}+24.3,
$$

Since $\log _{10} K_{\mathrm{Pu}-\mathrm{H}_{2} \mathrm{O}}=-0.06$ at I $=0.1 \mathrm{M} \mathrm{NaCl}$ using the new recommended value and the Specific Interaction Theory parameters, the new $\log K^{*}(\mathrm{Pu}-\mathrm{Tf})$ becomes 24.2 and not 22.7 , as previously calculated. This leads to a new conclusion that the affinity of Tf for Pu is higher than that for iron and not of a similar strength as previously reported. ${ }^{7,12}$ This conclusion is supported by our results (see Table 3) which show that at $\mathrm{pH} 6$ a free-bicarbonate binding constant for $\mathrm{Pu}$ is about $10^{4}$ times higher than that of iron at $\mathrm{pH}$ 6.7. An increase in the binding constant of $\mathrm{Pu}$ for $\mathrm{Tf}$ at $\mathrm{pH} 6.7$ is expected when the $\mathrm{pH}$ increases from 6.7 to 7.4 since it has been shown previously that the binding constant

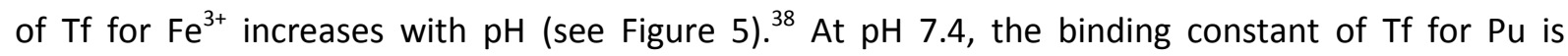
therefore expected to be $\log K_{1}^{*}=25.0$ (Figure 5). This evaluation, based on the analogy with $\mathrm{Fe}^{3+}$, has of course limitations but gives an acceptable value. ${ }^{36}$

Finally, the value proposed by Yule is an overall binding constant $\left(K^{*}\right)$ whereas we determined the first stepwise binding constant $\left(K_{1}^{*}\right)$ which is likely a $K_{C}^{*}$ constant. In addition, CE-ICP-MS has the advantage of being able to determine the second stepwise constant $K_{2}^{*}$. Indeed, at the metal saturation, the count rate obtained by ICP-MS in the band of migration containing $\mathrm{Pu}_{2} \mathrm{Tf}$ should be 
twice that obtained when only one Pu is bound to Tf. Unfortunately, it was not possible to obtain $K_{2}^{*}$ because it would have been necessary to increase the concentration of plutonium above the permitted level for the handling of radioactive matter. However, with a lower Tf concentration and a more sensitive ICP-MS, such a constant should be accessible. Such work would, however, be of prime interest in order to characterize the distribution of Pu-Tf species in blood.

Table 1: Binding constants from the literature

\begin{tabular}{|c|c|c|}
\hline Equilibrium & $\log K, 25^{\circ} \mathrm{C}, 0.1 \mathrm{M}$ & Reference \\
\hline $\mathrm{H}_{4} \mathrm{NTA}^{+} \rightleftharpoons \mathrm{H}_{3} \mathrm{NTA}+\mathrm{H}^{+}$ & $1.0 \pm 0.1$ & \multirow[t]{6}{*}{ Ref.23 } \\
\hline $\mathrm{H}_{3} \mathrm{NTA} \rightleftharpoons \mathrm{H}_{2} \mathrm{NTA}^{-}+\mathrm{H}^{+}$ & $1.82 \pm 0.10$ & \\
\hline $\mathrm{H}_{2} \mathrm{NTA}^{-} \rightleftharpoons \mathrm{HNTA}^{2-}+\mathrm{H}^{+}$ & $2.49 \pm 0.03$ & \\
\hline$H N T A^{2-} \rightleftharpoons N T A^{3-}+H^{+}$ & $9.68 \pm 0.04$ & \\
\hline $\mathrm{Pu}^{4+}+N T A^{3-} \rightleftharpoons P u N T A^{+}$ & $22.38 \pm 0.28$ & \\
\hline$P u^{4+}+2 N T A^{3-} \rightleftharpoons P u(N T A)_{2}^{2-}$ & $37.90 \pm 0.23$ & \\
\hline
\end{tabular}

Table 2: Experimental conditional binding constants $(*)$

\begin{tabular}{|c|c|c|}
\hline Equilibrium & $\log K^{*}$ & Reference / comments \\
\hline $\begin{array}{ll}\begin{array}{l}P u+T f \rightleftharpoons P u T f \\
\text { Synergistic anion, } p H:\end{array} & \text { NTA, } p H 6 \\
& \text { NTA, pH } 6 \\
2 P u+T f \rightleftharpoons P u_{2} T f & \text { (as considered in } \\
\text { ref.7) } & \text { Citrate, } p H 7.4\end{array}$ & $\begin{array}{l}24.62 \pm 0.24 \\
24.89 \pm 0.26 \\
22.45 \pm 0.62^{\phi \star}\end{array}$ & $\begin{array}{l}\text { this work, } I=0.1 \mathrm{M} \mathrm{NaCl} \text {, MES buffer } \\
\text { this work, } I=0.1 \mathrm{M} \mathrm{NaCl} \text { MES buffer } \\
\text { Ref.7, I=0.05M MES-HEPES buffer }\end{array}$ \\
\hline
\end{tabular}

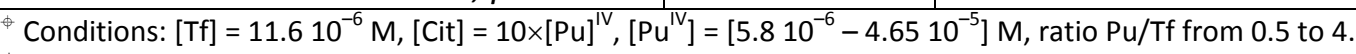

* Average of eight values varying from 21.75 to 24 . See explanation in the results paragraph.

Table 3: Conditional binding constants recalculated bicarbonate-free.

\begin{tabular}{|c|c|c|c|}
\hline Equilibrium & & Binding constants & Reference \\
\hline $\begin{array}{l}P u+T f \rightleftharpoons P u_{C} T f \\
\log _{10} K_{1}^{*}=\log _{10} K_{P u T f}^{*}+\log _{10} \alpha_{c}\end{array}$ & $\begin{array}{l}\text { pH } 6 \\
\text { Average }\end{array}$ & $\begin{array}{l}\log K_{1}^{*}=22.37 \pm 0.26 \\
\log K_{1}^{*}=22.64 \pm 0.28 \\
\log K_{1}^{*}=22.50 \pm 0.19\end{array}$ & $\begin{array}{l}\text { this work } \\
\text { this work } \\
\text { this work }\end{array}$ \\
\hline$P u+T f \rightleftharpoons P u T f$ & $\mathrm{pH} 7.4$ & $\log K^{*}=22.45 \pm 0.62$ & Ref.7 \\
\hline$F e+T f \rightleftharpoons F e T f$ & $\begin{array}{l}\mathrm{pH} 7.4 \\
\mathrm{pH} 6.7\end{array}$ & $\begin{array}{l}\log K^{*}=20.37 \pm 0.54 \\
\log K_{1}^{*}=19.5 \\
\log K_{1}^{*}=21.8 \\
\log K_{1}^{*}=18.1\end{array}$ & $\begin{array}{l}\text { Ref.7 } \\
\text { Ref.38 } \\
\text { Ref.27 } \\
\text { Ref.38 }\end{array}$ \\
\hline
\end{tabular}




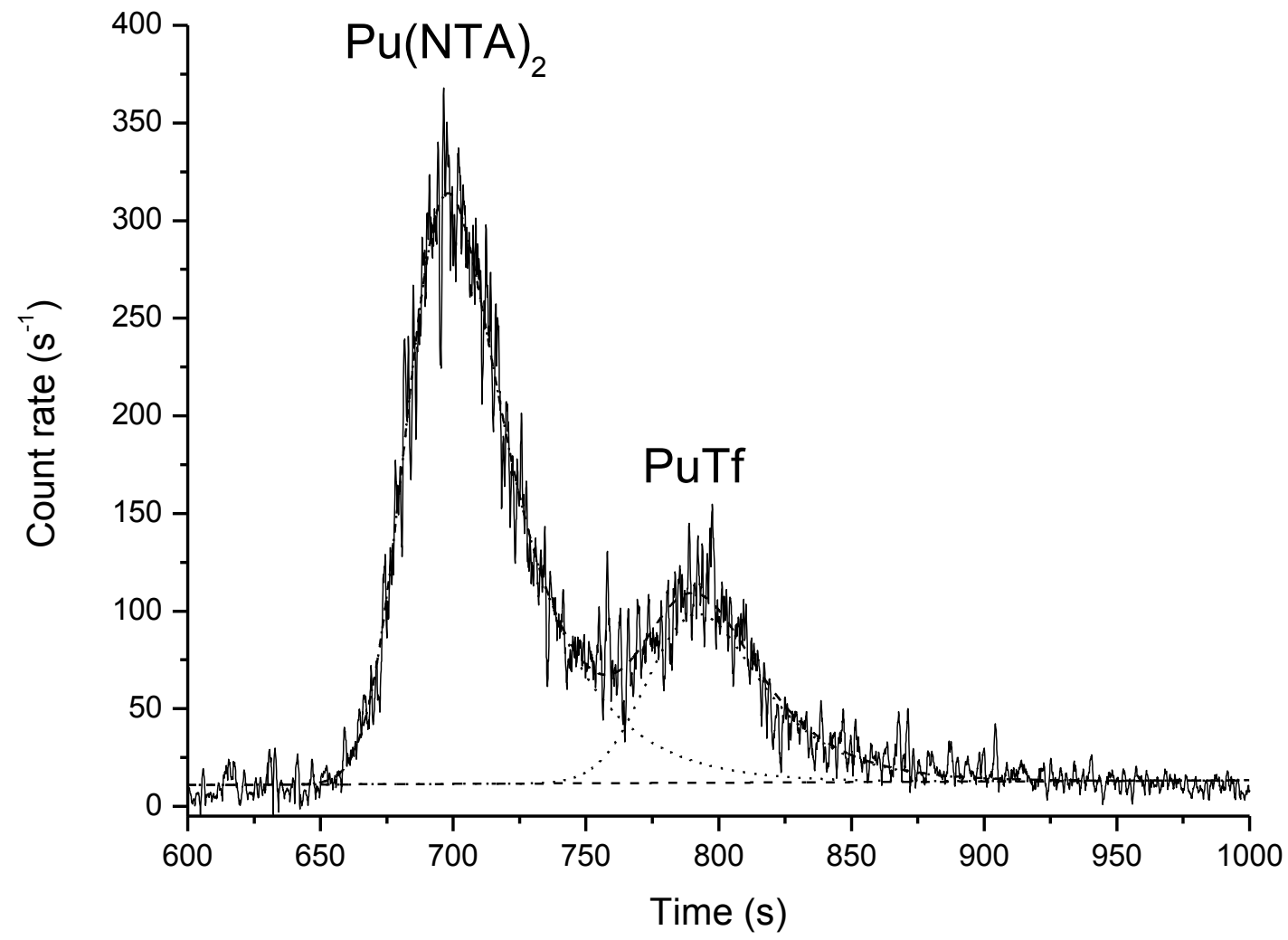

Figure 1: Electropherogram of Pu/NTA/Tf sample. Sample: $[\mathrm{Pu}]=10^{-10} \mathrm{M},[\mathrm{NTA}]=1 \mu \mathrm{M},[\mathrm{Tf}]=4.710^{-8} \mathrm{M}, \mathrm{pH} 6.0$, $\mathrm{NaCl} / \mathrm{MES}$ buffer, $\mathrm{I}=0.1 \mathrm{M}$. Conditions of separation: $25^{\circ} \mathrm{C}, \mathrm{V}=+5 \mathrm{kV}$, capillary $\mathrm{N}-\mathrm{CHO}^{\mathrm{TM}}$ from Beckman Coulter, $\mathrm{L}=65$ $\mathrm{cm}$, internal diameter $50 \mu \mathrm{m}$. The peak areas were determined by minimizing an exponentially modified Gauss function with the Levenberg-Marquardt algorithm. 


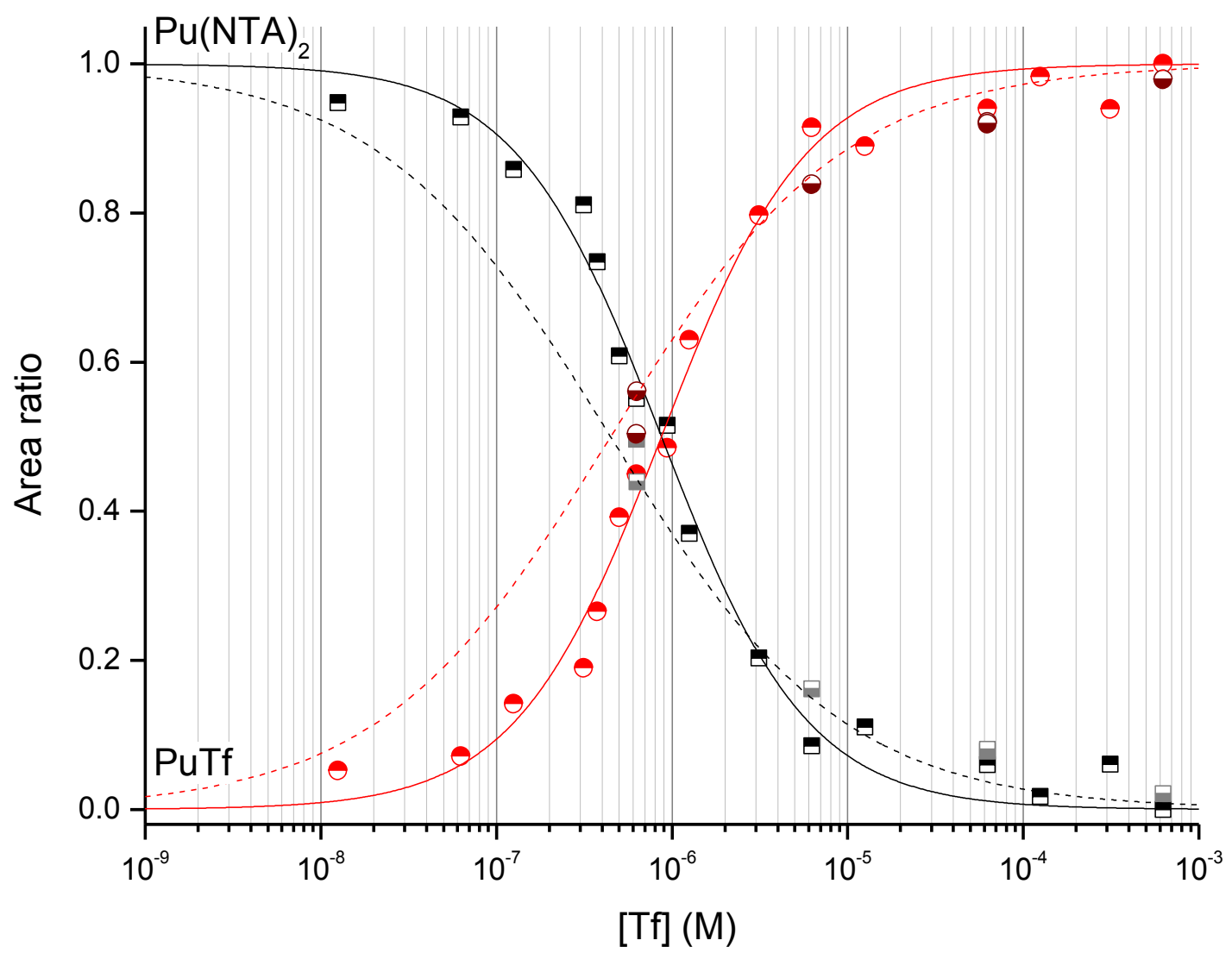

Figure 2: Area variation of Pu(NTA) ${ }_{2}$ (square symbols) and PuTf (round symbols) peaks as function of [Tf] by using two different coated capillaries $\mathrm{N}-\mathrm{CHO}^{\mathrm{TM}}$ (full line) and Neutral ${ }^{\mathrm{TM}}$ (dash line). The equivalence point is found to be at $[\mathrm{Tf}]=(8.7$ $\pm 1.1) 10^{-7} \mathrm{M}$ for $\mathrm{N}-\mathrm{CHO}^{\mathrm{TM}}$ and $[\mathrm{Tf}]=(4.8 \pm 1.5) 10^{-7} \mathrm{M}$ for Neutral ${ }^{\mathrm{TM}}$. Conditions of separation: $25^{\circ} \mathrm{C}, \mathrm{V}=+5 \mathrm{kV}$, capillary $\mathrm{N}-\mathrm{CHO}^{\mathrm{TM}}$ from Beckman Coulter, $\mathrm{L}=65 \mathrm{~cm}$, internal diameter $50 \mu \mathrm{m}, \mathrm{C}_{\mathrm{NTA}}=10^{-6} \mathrm{M}, \mathrm{pH} 6.0, \mathrm{NaCl} / \mathrm{MES}$ buffer, $\mathrm{I}=0.1 \mathrm{M}$, $\left[\mathrm{Pu}^{\mathrm{IV}}\right]=10^{-10} \mathrm{M}$. 


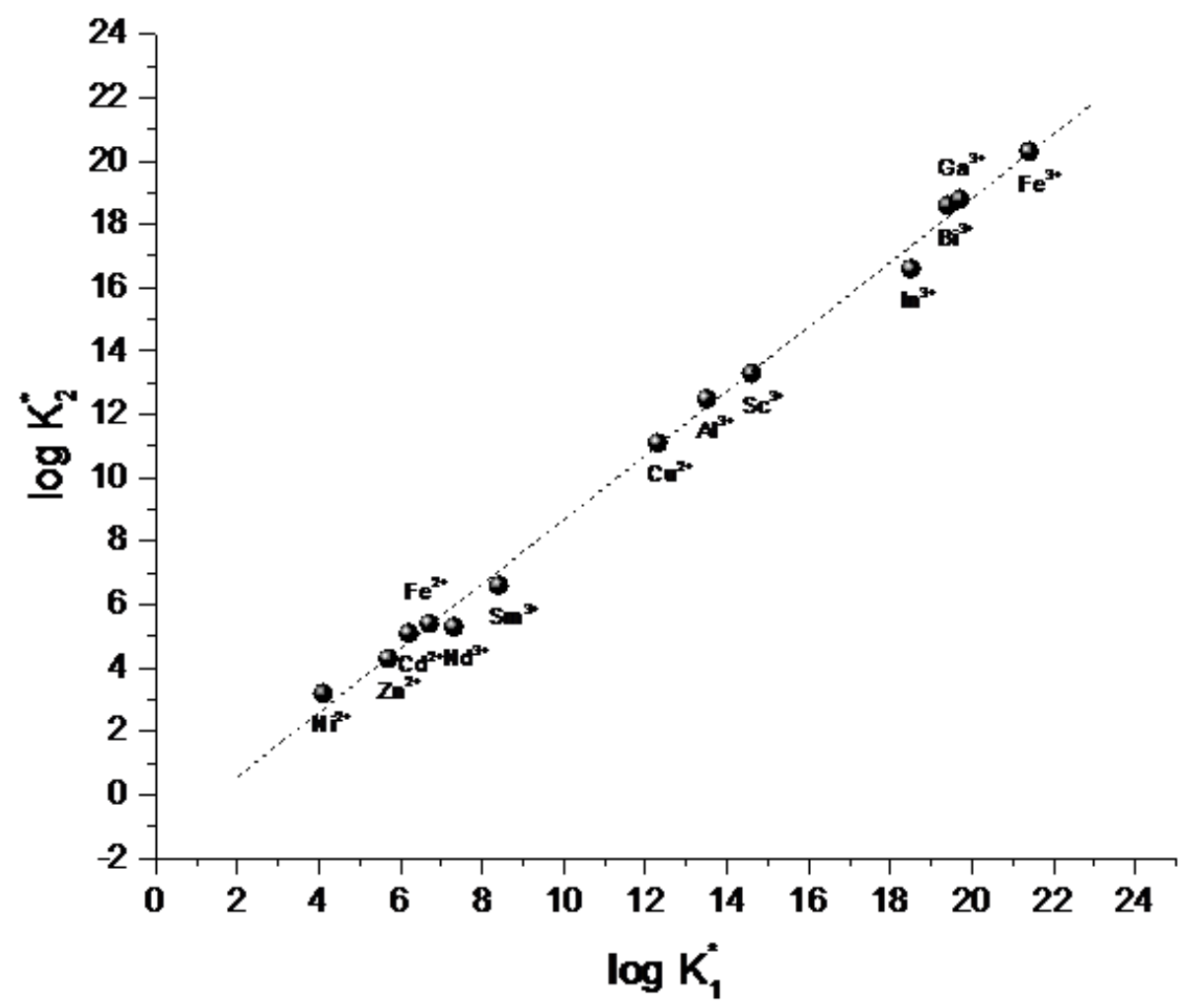

Figure 3: Correlation between the binding constants $K_{1}^{*}$ and $K_{2}^{*}$ for various metals and human transferrin, from the data of Sun et al. ${ }^{33}$ 


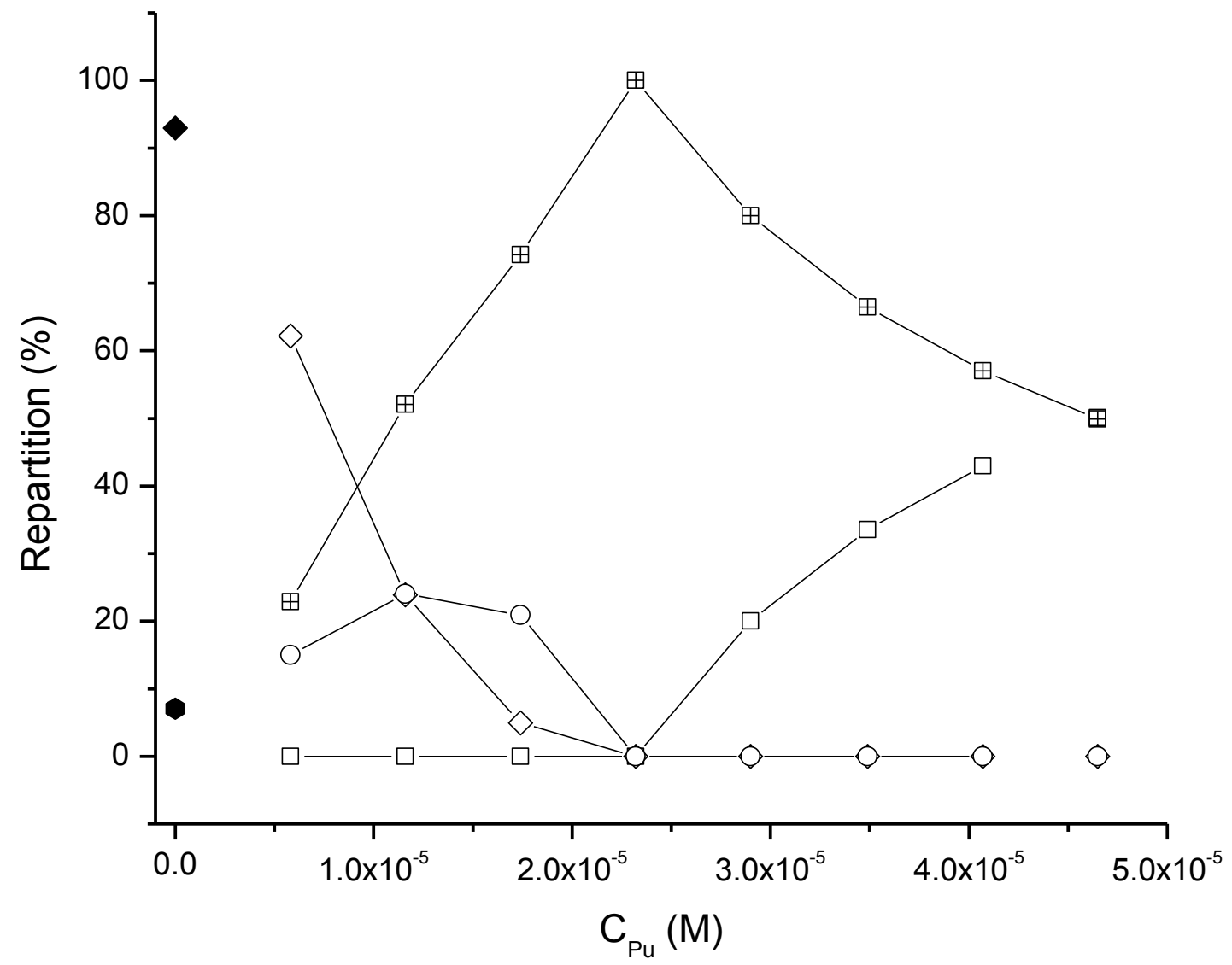

Figure 4: Theoretical distribution of free $\mathrm{Pu}, \mathrm{Pu}_{\mathrm{C}} \mathrm{Tf}, \mathrm{TfPu}_{\mathrm{N}}$, and $\mathrm{Pu}_{2} \mathrm{Tf}$ in the experiments of Yule as a function of the total concentration of plutonium. The following binding constants have been used: ${ }^{12} \log K_{1, C}^{*}=23.88 ; \log K_{1, N}^{*}=22.76$; $\log K_{2, C}^{*}=22.77 ; \log K_{2, N}^{*}=21.63 . \log K_{2, C}^{*}$ and $\log K_{2, N}^{*}$ have been determined thanks to correlation depicted in the Figure 3. Since both constants represent the same final species $\mathrm{Pu}_{2} \mathrm{Tf}$, their contributions have been added $(\boxplus)$. $\square \mathrm{Pu}, \diamond$

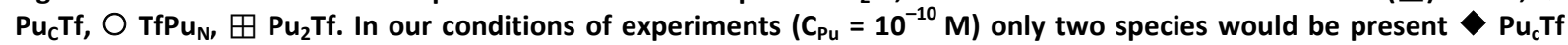
(92.95\%), and $\operatorname{TfPu}_{\mathrm{N}}(7.05 \%)$. 


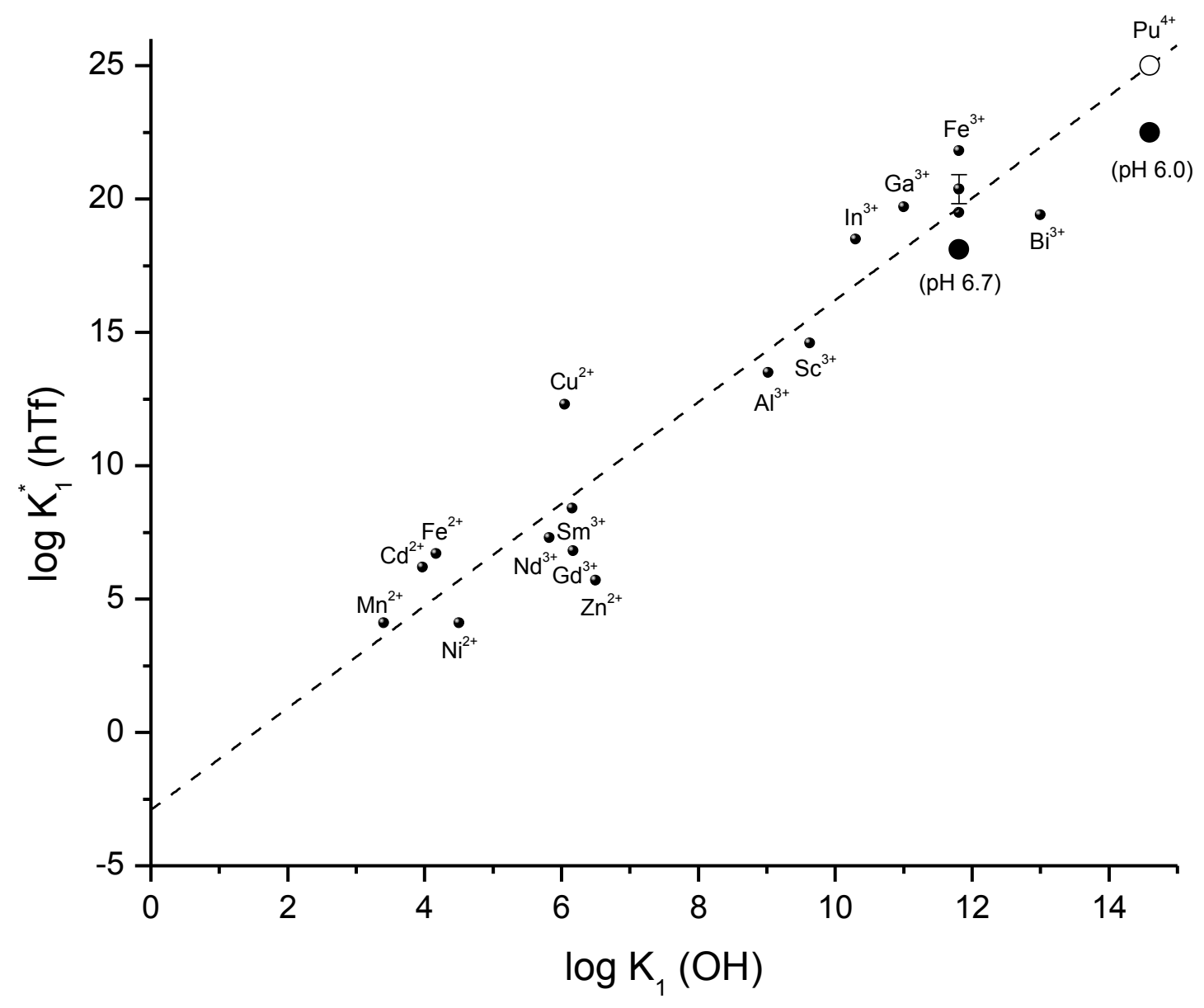

Figure 5: Correlation of the first metal binding constant of human transferrin (hTf) and various metals with the hydroxide binding (from references $7,26,27,33,38$ ) at pH 7.4. Value obtained by this study for Pu at $\mathrm{pH} 6.0$ and from ref. 38 for $\mathrm{Fe}^{3+}$ at pH 6.7. At pH 7.4 (O), the binding constant is expected to be $\log K_{1}^{*}=25.0$.

\section{$\square$ CONCLUSIONS}

In this study, the conditional constant relative to the formation of the Tf-Pu complex has been determined unambiguously by capillary electrophoresis coupled with an inductively coupled plasma mass spectrometer and using competition of Tf with the synergistic NTA anion. It is the first time that CE-ICP-MS has been used to determine the binding constant of Tf for Pu and more generally, it is also the first time that a binding constant of a protein for Pu has been determined by this method. Our experimental conditions allowed an ideal competition between Tf and NTA and the use of extremely low concentrations of metals, conditions in which hydrolysis reactions of Pu are suppressed. This resulted in highly reproducible experimental data. To compare and discuss our results with those obtained by Yule, ${ }^{6,7}$ the carbonate contribution was subtracted from the conditional binding constant leading to a conditional bicarbonate-free binding constant. Our results agree with those obtained by Yule but recorded under different experimental conditions. ${ }^{6,7}$ In addition, our results confirm a strong affinity of $\mathrm{Tf}$ for $\mathrm{Pu}$ and suggest that under physiological conditions the binding would be about $10^{4}$ times stronger than that of iron. Our approach opens the way to determine new binding constants by CE-ICP-MS of other proteins for metals in general but also particularly for toxic metals or radionuclides which could be used in smaller amounts in view of their (radio)toxicity. It also opens the possibility of obtaining other stepwise constants for any metal by CE-ICP-MS in the case of 
multi-sited proteins. In particular, CE-ICP-MS could be used to determine the second stepwise binding constant $K_{2}^{*}$ essential for the understanding of the distribution and therefore the chemical behavior of Pu-Tf species in blood. However such work requires a highly sensitive ICP-MS in order to avoid having to carry out experiments in a glove-box due the high radioactivity of plutonium.

\section{Q EXPERIMENTAL SECTION}

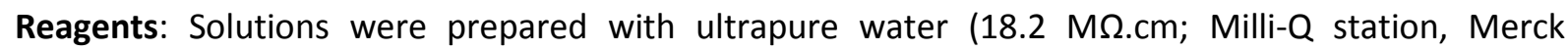
Millipore, Merck KGaA, Darmstadt, Germany). All experiments were performed using a background electrolyte (BGE) containing $80 \mathrm{mM} \mathrm{NaCl}, 57 \mathrm{mM}$ MES, and $1 \mu \mathrm{M}$ nitrilotriacetic acid (NTA). The $\mathrm{pH}$ was adjusted at $\mathrm{pH} 6.0$ by $\mathrm{NaOH}$. The ionic strength was $0.1 \mathrm{M}$. The solution of ${ }^{242} \mathrm{Pu}$ in BGE was prepared from a stock solution in $4 \mathrm{M} \mathrm{HNO}_{3}$. An aliquot of $1 \mathrm{~mL}$ was evaporated to dryness then 500 $\mu \mathrm{L}$ of $12 \mathrm{M} \mathrm{HCl}$ was added and the solution was once more evaporated to dryness. The latter operation was repeated three times. After the last evaporation, the sample was cooled to room temperature and $100 \mu \mathrm{L}$ of BGE was added. The final concentration of Pu stock solution was $10^{-9} \mathrm{M}$. The metal-binding ligand, transferrin, was prepared as described below. All the chemicals were obtained from commercial manufacturers and used as supplied.

Transferrin purification: Human transferrin was purified from outdated human plasma as described by Devanur et al. ${ }^{24}$ Briefly, solid ammonium sulphate was added to plasma to a saturation of $45 \%$ $(\mathrm{w} / \mathrm{v})$. After removal of the precipitate by centrifugation further ammonium sulphate was added to a final concentration of $70 \%(\mathrm{w} / \mathrm{v})$. The precipitate was recovered by centrifugation, redissolved in 50 $\mathrm{mM}$ sodium bicarbonate and fractionated on DEAE-Sepharose equilibrated with $20 \mathrm{mM}$ Tris/ $\mathrm{HCl}, \mathrm{pH}$ 8.0.

Preparation of iron-free human transferrin (ApoTf): Human transferrin was made iron-free as described by Evans and Williams. ${ }^{25}$ Briefly, transferrin was dialysed against of $0.1 \mathrm{M}$ citric acid, $\mathrm{pH}$ 4.7, and the ferric citrate so produced was removed by passage through the anion-exchange resin Bio-Rad AG1. The protein solution was then dialysed exhaustively against deionised water prior to lyophilisation.

CE-ICP-MS: A Beckman Coulter P/ACE 800 Plus commercial Capillary Electrophoresis (CE) system equipped with a diode array detector (Beckman Coulter, Fullerton, USA) was used for all the measurements. The measurements were carried out using two kinds of commercially-coated silica capillaries (Neutral capillary and $\mathrm{N}-\mathrm{CHO}$ capillary, both from Beckman Coulter), $50 \mu \mathrm{m}$ internal diameter, $65 \mathrm{~cm}$ total length, $10.1 \mathrm{~cm}$ optical window. The capillaries were preconditioned by rinsing with BGE before use at $10 \mathrm{psi}$ for $5 \mathrm{~min}$. The CE system was provided with a tailor-made capillary cartridge support designed for the adaptation of an external detector, i.e. a X Series" ICP-MS (Thermo). Both pieces of apparatus were coupled by a commercial interface using a parallel path micro-nebulizer (Mira Mist CE, Burgener, Mississauga, Canada) specially designed for capillary electrophoresis. A make-up liquid $\left(\mathrm{HNO}_{3} 2 \%\right.$ and ethyl alcohol absolute $\left.10 \%\right)$ was introduced by means of a syringe pump (11 Pico Plus, Harvard Apparatus, Holliston, MA) at a nominal flow rate of 7 $\mu \mathrm{L} . \mathrm{min}^{-1}$ to improve the signal stability by (i) decreasing the surface tension of the water droplets and the size of the droplets and (ii) providing the nominal flow rate for the nebulizer. Samples were injected at the capillary inlet over a period of $4 \mathrm{~s}$ at a constant pressure of $2 \mathrm{psi}$. Separations were performed at $+5 \mathrm{kV}, 25^{\circ} \mathrm{C}$ and a constant pressure of $0.5 \mathrm{psi}$ to avoid capillary clogging. The voltage value was chosen with respect to the Ohm's law and to avoid for temperature rises larger than $1{ }^{\circ} \mathrm{C}$ 
during the experiments. It should be pointed out that the temperature never decreased below $25^{\circ} \mathrm{C}$ but could rise to $26{ }^{\circ} \mathrm{C}$ by Joule heating, for the highest electrolyte conductivity. The buffer was changed every run to avoid the effects of electrolysis.

Pu-Tf samples preparation at various concentrations for CE-ICP-MS: A solution of apoTf was dialyzed 3 times against $57 \mathrm{mM}$ MES, $80 \mathrm{mM} \mathrm{NaCl}$ at pH6. The Pu-Tf samples were made as follows: each vial contained BGE, $1 \mu \mathrm{M}$ NTA, $0.1 \mathrm{nM}{ }^{242} \mathrm{Pu}$ and Tf concentrations varying from $0.627 \mathrm{mM}$ to $12.5 \mathrm{nM}$ in a final volume of $100 \mu \mathrm{L}$.

CE-ICPMS data treatment: The peak areas were determined by minimizing an exponentially modified gauss function by the Levenberg-Marquardt algorithm. Such a procedure makes it possible to take into account the small right-side tailing (see Figure 1). The Origin 7.0Pro software (OriginLab Corporation, Northampton MA, USA) was used to fit the electropherograms.

Determination of bicarbonate ion concentration by ionic chromatography: The international norm ISO 10304-1 (2009) is extended to the measurement of bicarbonate ions by adding it as a supplementary anion. A standardized stock solution of $\mathrm{Na}_{2} \mathrm{CO}_{3}$ at $1 \mathrm{~g} \cdot \mathrm{L}^{-1}$ (VWR, Haasrode, Belgium) was used for the external calibration.

\section{口 AUTHOR INFORMATION}

\section{Corresponding Author}

*e-mail: jean.aupiais@cea.fr; Fax: +33169267065

Notes: The authors declare no competing financial interest.

\section{ACKNOWLEDGEMENTS}

This work was funded by both the French CBRN Program and by the French transverse program "Toxicologie Nucléaire" under project name Inspector.

\section{Q REFERENCES}

(1) Cuttler, J. M.; Sanders, C. L. Dose-Response 2015, 13, doi: 10.1177/1559325815615102.

(2) Sokolnikov, M.; Dale, P.; Ethel, G.; Schonfeld, S.; Koshumikova, N. PloS One 2015, 10, e0117784.

(3) Nielsen, C. E.; Wang, X. H. Y.; Robinson, R. J.; Brooks, A. L.; Lovaglio, J.; Patton, K. M.; McComish, S. L.; Tolmachev, S. Y.; Morgan, W. F. Int. J. Rad. Biol. 2014, 90, 60-70.

(4) Taylor, D. M.; Seidel, A.; Planasbohne, F.; Schuppler, U.; Neumuller, M.; Wirth, R. E. Inorg. Chim. Acta 1987, 140, 361-363.

(5) Morss, L. R.; Edelstein, N. M.; Fuger, J., Eds. The chemistry of the actinide and transactinide elements, Third Edition ed.; Springer: Dordrecht, 2006.

(6) Jensen, M. P.; Gorman-Lewis, D.; Aryal, B.; Paunesku, T.; Vogt, S.; Rickert, P. G.; Seifert, S.; Lai, B.; Woloschak, G. E.; Soderholm, L. Nat. Chem. Biol. 2011, 7, 560-565.

(7) Yule, L., University of Wales, Cardiff, 1991.

(8) Stover, B. J.; Bruenger, F. W.; Stevens, W. Radiat. Res. 1968, 33, 381-394.

(9) Sun, H.; Li, H.; Sadler, P. J. Chem. Rev. 1999, 99, $2817-2842$.

(10) Sargent, P. J.; Farnaud, S.; Evans, R. W. Curr. Med. Chem. 2005, 12, 2683-2693.

(11) Bou-Abdallah, F.; Terpstra, T. R. Biochim. Biophys. Acta 2012, 1820, 318-325.

(12) Ansoborlo, E.; Prat, O.; Moisy, P.; den Auwer, C.; Guilbaud, P.; Carrière, M.; Gouget, B.; Duffield, J.; Doizi, D.; Vercouter, T.; Moulin, C.; Moulin, V. Biochimie 2006, 88, 1605-1618.

(13) Gorden, A. E. V.; Xu, J.; Raymond, K. N.; Durbin, P. Chem. Rev. 2003, 103, 4207-4282.

(14) Brock, J. H. In Metalloproteins, part 2; Harrison, P. M., Ed.; Verlag Chemie: Weinheim, 1995, pp 183-261.

(15) Vincent, J. B.; Love, S. Biochim. Biophys. Acta 2012, 1820, 362-378. 
(16) Vidaud, C.; Gourion-Arsiquaud, S.; Rollin-Genetet, F.; Torne-Celer, C.; Plantevin, S.; Pible, O.; Berthomieu, C.; Quéméneur, E. Biochemistry 2007, 46, 2215-2226.

(17) Pardoux, R.; Sauge-Merle, S.; Lemaire, D.; Delangle, P.; Guilloreau, L.; Adriano, J. M.; Berthomieu, C. PloS One 2012, 7, e41922.

(18) Beccia, M. R.; Sauge-Merle, S.; Lemaire, D.; Bremond, N.; Pardoux, R.; Blangy, S.; Guilbaud, P.; Berthomieu, C. J. Biol. Inorg. Chem. 2015, 20, 905-919.

(19) Creff, G.; Safi, S.; Roques, J.; Michel, H.; Jeanson, A.; Solari, P. L.; Basset, C.; Simoni, E.; Vidaud, C.; den Auwer, C. Inorg. Chem. 2016, 55, 29-36.

(20) Topin, S.; Aupiais, J.; Baglan, N. Radiochim. Acta 2010, 98, 71-75.

(21) Chasteen, N. D.; Williams, J. Biochem. J. 1981, 193, 717-727.

(22) Graser, C. H.; Banik, L. N.; Bender, K. A.; Lagos, M.; Marquardt, C. M.; Marsac, R.; Montoya, V.; Geckeis, H. Anal. Chem. 2015, 87, 9786-9794.

(23) Bonin, L.; Aupiais, J.; Kerbaa, M.; Moisy, P.; Topin, S.; Siberchicot, B. RSC Adv. 2016, 6, 62729-62741.

(24) Devanur, L. D.; Evans, R. W.; Evans, P. J.; Hider, R. C. Biochem. J. 2008, 409, 439-447.

(25) Evans, R. W.; Williams, J. Biochem. J. 1978, 173, 543-552.

(26) Li, H.; Sadler, P. J. Eur. J. Biochem. 1996, 242, 387-393.

(27) Martin, R. B.; Savory, J.; Brown, S.; Bertholf, R. L.; Wills, M. R. Clin. Chem. 1987, 33, 405-407.

(28) Li, H.; Sadler, P. J.; Sun, H. J. Biol. Chem. 1996, 271, 9483-9489.

(29) Duffield, J. R.; Taylor, D. M. Inorg. Chim. Acta 1987, 140, 365-367.

(30) Jeanson, A.; Ferrand, M.; Funke, H.; Hennig, C.; Moisy, P.; Solari, P. L.; Vidaud, C.; Den Auwer, C. Chem. Eur. J. 2010, 16, 1378-1387.

(31) Schlabach, M. R.; Bates, G. W. J. Biol. Chem. 1975, 250, 2182-2188.

(32) Harris, W. R.; Chen, Y.; Wein, K. Inorg. Chem. 1994, 33, 4991-4998.

(33) Sun, H.; Li, H.; Sadler, P. J. Chem. Rev. 1999, 99, 2817-2842.

(34) Harris, W. R. Biochem. 1985, 24, 7412-7418.

(35) Sun, H.; Cox, M. C.; Li, H.; Sadler, P. J. In Structure and Bonding; Springler Verlag: Berlin, 1997; Vol. 88, pp 71-102.

(36) Guillaumont, R.; Fanghänel, T.; Neck, V.; Fuger, J.; Palmer, D. A.; Grenthe, I.; Rand, M. H. Update on the chemical thermodynamics of uranium, neptunium, plutonium, americium and technetium, OECD ed.; Elsevier: Amsterdam, 2003.

(37) Lemire, R. J. Chemical Thermodynamics of Neptunium and Plutonium, OECD ed.; North-Holland: Amsterdam, 2001.

(38) Aisen, P.; Leibman, A.; Zweier, J. J. Biol. Chem. 1978, 253, 1930-1937. 